\title{
ASO Author Reflections: Optimizing the Oncological Outcome for Locally Advanced Intrahepatic Cholangiocarcinoma
}

\author{
Jun Li, MD (D) , M. Moustafa, MD, PhD, J. Meiners, MD, O. Stüben, MD, J. Izbicki, MD, and \\ A. Heumann, MD \\ Department of General, Visceral and Thorax Surgery, University Medical Center Hamburg-Eppendorf, Hamburg, \\ Germany
}

\section{PAST}

Intrahepatic cholangiocarcinoma (ICC) is an uncommon disease. Nevertheless, a recent review of the SEER database demonstrated that there has been a 10-fold increase in cholangiocarcinoma-related mortality since $1973 .{ }^{1}$ According to recent guidelines, liver resection is the only curative treatment for ICC. An adequate remnant liver volume is one of the limiting factors in ensuring an R0 resection. $^{2,3}$ Associating liver partition and portal vein ligation for staged hepatectomy (ALPPS) could increase the resectability in advanced primary and secondary liver malignancies. However, concerns were raised due to the resulting high postoperative morbidity and mortality as well as unknown oncological benefit in non-colorectal metastasis settings. ${ }^{4,5}$

\section{PRESENT}

In the registry cohort study from 31 international institutes, 102 patients with locally advanced ICC undergoing ALPPS were recruited. ${ }^{6}$ The R0 resection rate was $85 \%$. The initial high morbidity and mortality rates decreased

ASO Author Reflections is a brief invited commentary on the article, "ALPPS for locally advanced intrahepatic cholangiocarcinoma: did aggressive surgery lead to the oncological benefit?-An international multi-center study," Ann Surg Oncol. (2020). https://doi.org/10.1245/ s10434-019-08192-z.

(C) The Author(s) 2020

First Received: 25 January 2020;

Published Online: 2 March 2020

J. Li, MD

e-mail: j.li@uke.de steadily to a $29 \%$ severe complication rate and $7 \%$ 90-day mortality in the last 2 years. Multivariate analysis revealed insufficient future liver remnant at stage-2 operation (FLR2) to be the only risk factor for severe complications. A superior overall survival was found in the ALPPS group compared to the propensity score matched palliative chemotherapy group from the SEER database (26.4 months vs 14 months in median). A survival benefit was not confirmed in the subgroup of patients with multifocal ICC. The authors therefore recommend ALPPS to be performed only in ICC patients with a single lesion at this stage and a sufficient FLR2 must be ensured. A high recurrence rate remains an unsolved problem for this disease.

\section{FUTURE}

Generally, locoregional recurrence occurs in $60 \%$ and distant recurrence in $30 \%$ following liver resection for ICC. ${ }^{7}$ During the period of liver regeneration after hepatectomy, it is anticipated that the remaining circulating tumor cells also receive growth stimulation, which would potentially result in local or distant recurrence. ${ }^{8}$ To achieve a long-term disease-free survival after R0 resection, it is important to control these occult tumor cells before they are stimulated.

This rational provoked our research group to design a neoadjuvant chemotherapy regimen (NEOMAIC trial) in this group of patients, who are going to experience an overwhelming regenerating process under ALPPS or conventional portal vein embolization. Due to the rarity of the disease, the current treatment recommendations in both the adjuvant and neoadjuvant settings are based on a paucity of Phase III trial data. Complicating this further, most of these datasets include patients with gallbladder disease and 
extrahepatic cholangiocarcinoma. ${ }^{9,10}$ A clinical trial limited only to ICC, supported by highly specialized international institutes, would be the best approach to address this issue.

ACKNOWLEDGEMENTS Open Access funding provided by Projekt DEAL.

DISCLOSURES The authors report no conflicts of interest.

OPEN ACCESS This article is licensed under a Creative Commons Attribution 4.0 International License, which permits use, sharing, adaptation, distribution and reproduction in any medium or format, as long as you give appropriate credit to the original author(s) and the source, provide a link to the Creative Commons licence, and indicate if changes were made. The images or other third party material in this article are included in the article's Creative Commons licence, unless indicated otherwise in a credit line to the material. If material is not included in the article's Creative Commons licence and your intended use is not permitted by statutory regulation or exceeds the permitted use, you will need to obtain permission directly from the copyright holder. To view a copy of this licence, visit http://creativecommons. org/licenses/by/4.0/.

\section{REFERENCES}

1. Nathan $\mathrm{H}$, et al. Trends in survival after surgery for cholangiocarcinoma: a 30-year population-based SEER database analysis. $J$ Gastrointest Surg. 2007;11(11):1488-97.

2. Bridgewater $\mathbf{J}$, et al. Guidelines for the diagnosis and management of intrahepatic cholangiocarcinoma. $J$ Hepatol. 2014;60(6):1268-89.
3. Benson $\mathrm{AB}$, et al. NCCN guidelines insights: hepatobiliary cancers, version 1.2017. J Natl Compr Cancer Netw. 2017;15(5): $563-73$.

4. Schadde E, et al. Monosegment ALPPS hepatectomy: extending resectability by rapid hypertrophy. Surgery. 2015;157(4):676-89.

5. Olthof PB, et al. High mortality after ALPPS for perihilar cholangiocarcinoma: case-control analysis including the first series from the international ALPPS registry. $H P B$. 2017;19(5):381-7.

6. Li J, Mohamed Moustafa M, Michael Linecker M, et al. ALPPS for locally advanced intrahepatic cholangiocarcinoma: did aggressive surgery lead to the oncological benefit?-an international multicenter study. Ann Surg Oncol. 2020. https://doi.org/ 10.1245/s10434-019-08192-z.

7. Yamamoto $\mathrm{M}$, et al. Recurrence after surgical resection of intrahepatic cholangiocarcinoma. J Hepato-Biliary-Pancreat Surg. 2001;8(2):154-7.

8. Mosconi C, et al. Yttrium-90 microsphere radioembolization in unresectable intrahepatic cholangiocarcinoma. Future Oncol. 2017;13(15):1301-10.

9. Jarnagin WR, D'Angelica M, DeMatteo RP, et al. Patterns of initial disease recurrence after resection of gallbladder carcinoma and hilar cholangiocarcinoma: implications for adjuvant therapeutic strategies. Cancer. 2003;98:1689-700.

10. Hasegawa S, et al. Surgical resection of hilar cholangiocarcinoma: analysis of survival and postoperative complications. World J Surg. 2007;31(6):1258-65.

Publisher's Note Springer Nature remains neutral with regard to jurisdictional claims in published maps and institutional affiliations. 